\title{
Nutritional status, dietary intake, and health- related quality of life in outpatients with COPD
}

This article was published in the following Dove Medical Press journal:

International Journal of COPD

\section{Ha Thanh Nguyen ${ }^{1,2}$ \\ Peter F Collins ${ }^{1,3}$ \\ Toby G Pavey' \\ Nhung Viet Nguyen ${ }^{4}$ \\ Tuong Duy Pham² \\ Danielle L Gallegos'}

'School of Exercise and Nutrition Sciences, Faculty of Health

Queensland University of Technology, Kelvin Grove, QLD, Australia;

${ }^{2}$ Department of Nutrition and

Food Safety, Institute for Preventive

Medicine and Public Health, Hanoi

Medical University, Hanoi, Vietnam;

${ }^{3}$ Department of Nutrition and

Dietetics, Princess Alexandra Hospital,

Brisbane, Australia; ${ }^{4}$ National Lung

Hospital, Hanoi, Vietnam
Correspondence: Ha Thanh Nguyen School of Exercise and Nutrition Sciences, Faculty of Health, Queensland University of Technology, Victoria Park Road, QLD 4059, Brisbane, Australia Tel +61731389199

Email thanhha.nguyen@hdr.qut.edu.au
Background: Malnutrition is common in patients with COPD; however, little is known about its impacts on health-related quality of life (QoL) among patients with COPD. This study aimed to explore the nutritional status and dietary intake among outpatients with COPD in Vietnam and its possible associations with QoL.

Methods: A cross-sectional study was carried out in COPD outpatients visiting the COPD management unit at the National Lung Hospital, Hanoi, Vietnam between May 2017 and July 2017. Consecutive outpatients with a confirmed diagnosis of COPD were recruited with written inform consent. The nutritional status of participants was assessed using Subjective Global Assessment (SGA), and dietary intake via a 24-hour recall interview. The St George Respiratory Questionnaire (SGRQ) for COPD was used to investigate the participants' QoL. Sociodemographic and clinical data were extracted from hospital records.

Results: Of 168 COPD outpatients involved in the study, three-quarters (74.4\%) were diagnosed as malnourished (SGA B/C) and $81.5 \%$ reported unintentional weight loss. Most of the patients did not meet their estimated energy and protein requirements ( $85.7 \%$ and $89.9 \%$, respectively). Malnutrition was significantly associated with disease severity $(P=0.039)$ and ratio of protein intake to estimated requirement $(P=0.005)$. QoL was low for all levels of malnutrition or disease severity, with well-nourished participants and those with less disease severity having better QoL ( $P=0.006$ and $P<0.001$, respectively). With an extra meal per day, the odds of having malnutrition decreased 5.6 times $(P<0.05)$ and the total SGRQ reduced 3.61 scores $(P<0.05)$ indicating a better QoL.

Conclusion: Malnutrition and weight loss are prevalent among COPD outpatients. Most of the patients had inadequate dietary intake and low QoL. Nutrition counselling including increasing the number of meals per day with a focus on energy- and protein-rich foods may help improving nutritional status and QoL of patients with COPD in Vietnam.

Keywords: body weight, energy intake, protein intake, SGRQ, COPD, Vietnam

\section{Introduction}

COPD prevalence has increased globally over recent decades, affecting 328 million people worldwide. ${ }^{1}$ In 2015, total deaths from COPD were 3.2 million $^{2}$ and are forecasted to increase by more than $30 \%$ in the next decade. This will make COPD the third leading cause of death worldwide by the year $2030 .{ }^{3}$ While COPD prevalence is estimated to be $4.7 \%$ globally, ${ }^{1}$ the overall estimated COPD prevalence in Asia is $6.2 \%,{ }^{4}$ with a prevalence of $8.5 \%$ in Japan $^{5}$ and $13.6 \%$ in China. ${ }^{6}$ A recent study found COPD prevalence among nonsmokers in Vietnam to be $8.1 \%,{ }^{7}$ suggesting that COPD prevalence among smokers may be much higher. COPD is therefore a major public health concern. In addition to smoking, air pollution and an aging population is contributing to rising rates, especially in low- and middle-income countries. ${ }^{8}$ 
Malnutrition is common among people with COPD and is often associated with poor prognosis. ${ }^{9}$ The prevalence of malnutrition in outpatients with COPD is $10 \%-45 \%{ }^{10}$ and may be higher in low-middle-income countries including Vietnam. ${ }^{11,12}$ Malnutrition adversely affects pulmonary function, decreases health-related quality of life (HRQL), and increases the risk of exacerbations, length of hospital stay, and healthcare costs. ${ }^{10,13-15}$ Inadequate dietary intake is the most commonly cited reason for malnutrition in COPD patients. ${ }^{16,17}$ Previous studies have shown that nutrition interventions could result in significant improvements in functional capacity and quality of life (QoL) as well as decreasing morbidity and mortality for COPD patients. ${ }^{18,19}$ However, most of those studies focus on supplementary intervention, ${ }^{20}$ and few investigate potential and specific factors that may alter nutritional status, dietary intake, and QoL of patients with COPD.

In addition, to date, a majority of studies exploring nutritional status or nutrition interventions in COPD patients come from high-income countries rather than low- and middle-income countries. ${ }^{20}$ Limited studies in this field have been conducted in the Asia-Pacific region ${ }^{21}$ with only one known study in Vietnam. ${ }^{12}$ This study aims to explore the nutritional status and dietary intake of outpatients with COPD in Vietnam and investigates their association with QoL. This study will inform the development of appropriate nutrition intervention strategies to improve the nutritional status, functional capacity, and thus QoL of patients with COPD living in Vietnam.

\section{Methods}

\section{Study design and participants}

This observational cross-sectional study had been registered in Australian New Zealand Clinical Trials Registry (ANZCTR) and allocated the ACTRN: ACTRN12618000625279 and was conducted in the National Lung Hospital (NLH), Hanoi, Vietnam, between May 2017 and July 2017. All outpatients who presented to the COPD Management Unit (CMU), NLH for management of their disease were approached. Only outpatients with a confirmed diagnosis of COPD, defined as predicted $\mathrm{FEV}_{1}<80 \%$ and $\mathrm{FEV}_{1} / \mathrm{FVC}<0.7$, were invited to participate. COPD disease severity was classified according to the Global Initiative for Chronic Obstructive Lung Disease criteria. ${ }^{3}$ All patients with a confirmed diagnosis, regardless of comorbidities, were invited to take part.

A total of 302 patients presented at the CMU during the study period. Of these, 177 patients were confirmed with COPD, by CMU doctors, and all of these were approached. Nine patients were excluded from the study due to the following: one patient was deaf, five patients were hospitalized on the day of visit due to exacerbations, and three patients declined to participate. Therefore, the participation rate was 94.9\% (Figure S1).

Written informed consent was obtained from each participant following a detailed explanation of the study purposes and procedure. The study was conducted in accordance with the Declaration of Helsinki and was granted ethical approval from the Human Research Ethics Committees of the Queensland University of Technology (QUT), Brisbane, Australia (QUT ethics approval number: 1600000959) and the NLH, Hanoi, Vietnam (NLH ethics approval number: 462/2016/NCKH).

\section{Measurement}

The principal investigator provided comprehensive training on data collection to all nursing and technical staff who were involved as research team members. Socioeconomic and demographic data were collected by a trained triage nurse using a structured questionnaire. Variables included age, gender, smoking status (active smoker, used to smoke, or never smoked), and total smoking years. Clinical information such as lung function (judged by $\mathrm{FEV}_{1} \%$ predicted) or disease severity were extracted from the participants' medical records by the trained triage nurse.

Participants' nutritional status was assessed by the principal investigator using Subjective Global Assessment (SGA) as a "gold standard" to diagnose malnutrition and was categorized as SGA-A, no signs of malnutrition; SGA-B, mild or moderate malnutrition; and SGA-C, severe malnutrition. ${ }^{22}$ Anthropometric measurements including height, weight, mid-arm circumference (MAC), triceps skinfolds (TSF), and calf were performed by a trained technical staff of the CMU. Height was measured to the nearest $0.1 \mathrm{~cm}$ barefooted using a wall-mounted stadiometer. Weight was measured to the nearest $0.1 \mathrm{~kg}$ in light clothing using a digital weighing scale. Body mass index (BMI) was calculated as weight divided by height squared $\left(\mathrm{kg} / \mathrm{m}^{2}\right)$. BMI categories for Asians according to the WHO classifications were used in this study: $<18.5 \mathrm{~kg} / \mathrm{m}^{2}$ (underweight), $18.5-22.9 \mathrm{~kg} / \mathrm{m}^{2}$ (healthy), $23.0-27.49 \mathrm{~kg} / \mathrm{m}^{2}$ (overweight), and $27.5 \mathrm{~kg} / \mathrm{m}^{2}$ or higher (obesity). ${ }^{23}$ Patients also reported on weight loss in the past 6 months. MAC and calf circumference were measured with a single standard measuring tape. Skinfold calipers were used to measure TSF and the actual skinfold thickness was reported in millimeters. Mid-arm muscle circumference (MAMC) provides an index of muscle mass, calculated as: $\operatorname{MAMC}(\mathrm{cm})=\operatorname{MAC}(\mathrm{cm})-[3.14 \times \operatorname{TSF}(\mathrm{cm})]$. 
The St George Respiratory Questionnaire for COPD (SGRQ-C) was used to score the HRQL in COPD. This tool was developed and validated based on the original SGRQ which is considered as the gold standard to evaluate HRQL in respiratory disease patients. SGRQ-C is specific for COPD and consists of 40 items in three groups related to symptoms, activities, and impacts. ${ }^{24}$ Each score ranges from 0 (no impairment) to 100 (worst possible), a lower score represents a better HRQL. ${ }^{25}$ Apart from the validation for the original English version of SGRQ-C, this instrument has been validated in other population groups of Asian countries. ${ }^{26}$ In the present study, the face validity of the Vietnamese version of SGRQ-C instrument was confirmed by a pilot test. Irrelevant words, related to differing cultural contexts, such as playing golf and shoveling snow, were removed. The instrument's reliability was investigated by two administrations at an interval of 1 month on 30 participants with COPD. The Cronbach's alpha coefficient had high values exceeding 0.7 for all component scores (symptom: 0.822, activity: 0.910, impact: 0.948). The intraclass correlation coefficients for the symptom, activity, impact, and total scores were high, ranging from 0.722 to 0.834. Therefore, the SGRQ-C Vietnamese version was suitable to evaluate HRQL for COPD patients in Vietnam.

Dietary intake of participants was collected via a 1 day (24 hours) recall. Food records were entered by the principal researcher into the National Institute of Nutrition software for dietary intake analysis, which uses the Vietnamese food composition tables database. ${ }^{27}$ Energy and protein intakes were expressed as $\mathrm{kcal} / \mathrm{kg}$ actual body weight per day and $\mathrm{g} / \mathrm{kg}$ actual body weight per day, respectively. Estimated energy requirement (EER) and estimated protein requirement (EPR) were calculated according to $30-40 \mathrm{kcal} / \mathrm{kg}$ actual body weight per day and $1.2-1.5 \mathrm{~g}$ protein $/ \mathrm{kg}$ actual body weight per day for COPD patients identified as well-nourished (SGA-A), mild/moderately malnourished (SGA-B), and severely malnourished (SGA-C), respectively, as recommendations of energy and protein intakes for malnourished elderly participants. ${ }^{28-32}$ Given that COPD is primarily diagnosed in older age groups and malnutrition is progressive and affects mainly the elderly, using targets for older people was indicated. ${ }^{33}$

\section{Statistical analysis}

Sociodemographic, behavioral, and health-related characteristics of all participants by malnutrition category are described (n, \%). Differences were assessed using chi-squared tests for categorical variables and ANOVA for continuous variables. ANOVA Kruskal-Wallis $H$ test was used for nonparametric variables. Logistic regression was performed for prediction of malnutrition and dichotomized normal nutrition status (SGA-A; referent) or malnourished (SGA-B or C). Age, gender, years smoked, number of exacerbations in the last year, $\mathrm{FEV}_{1} \%$, \%EER, number of daily meals, and BMI were entered as independent variables. Multiple regression analyses were performed for the prediction of total SGRQ and subcategories of symptoms, activity, and impact. Age, gender, and years smoked were entered at Block 1. Number of exacerbations in the last year and $\mathrm{FEV}_{1} \%$ were entered at Block 2. Then to explore the influence of nutrition variables, $\%$ EER, number of daily meals, and BMI were entered at Block 3. Where data were nonnormally distributed, the twostep approach detailed by Templeton (2011) was applied. ${ }^{34}$ All statistical analyses were conducted in SPSS version 22.0 (IBM Corporation, Armonk, NY, USA). $P$-values were based on two-sided tests and were considered statistically significant at $P<0.05$. The current study has been reported according to internationally recognized guidelines: Strengthening the Reporting of Observational Studies in Epidemiology statement. $^{35}$

\section{Results}

\section{Participant characteristics}

The characteristics of study participants are described in Table 1. Of the 168 participants with a mean age of 63.9 years (SD: 8.5 ), $74.4 \%$ were identified as being malnourished according to the SGA classification: $41.7 \%$ SGA-B (mild or moderate malnutrition) and $32.7 \%$ SGA-C (severe malnutrition). The malnutrition prevalence remained high regardless of age and gender. A majority (85.1\%) were smokers with the mean number of smoking years being 30.8 years (SD: 16.3). Those participants in the severe malnutrition status demonstrated smoking for more years $(P<0.001)$.

Mean $\mathrm{FEV}_{1} \%$ was 49.3 (SD: 23.1), which categorized $8.3 \%$ of participants at a mild COPD stage, $32.1 \%$ at moderate, $40.5 \%$ at severe, and $19.0 \%$ at very severe COPD stage. The malnutrition rate was significantly higher in those with severe/very severe COPD compared to those with mild/ moderate COPD $(81.0 \%$ vs $64.7 \% ; P=0.018)$. Although those with severe malnutrition status displayed a worse lung function $\left(\mathrm{FEV}_{1} \%\right)$ this was not statistically significant.

Anthropometric indicators including BMI, MAC, TSF, MAMC, and calf circumference displayed significantly lower scores for those with severe malnutrition $(P<0.001)$. The mean BMI of study participants was $20.0 \mathrm{~kg} / \mathrm{m}^{2}$ (SD: 3.2 ). Participants with severe malnutrition displayed significantly lower BMI $\left(16.7 \mathrm{~kg} / \mathrm{m}^{2}\right.$, SD: $\left.1.5 ; P<0.001\right)$. 
Table I Participant characteristics and malnutrition status

\begin{tabular}{|c|c|c|c|c|c|}
\hline Variables & Total $(n=168)$ & SGA-A $(n=43)$ & SGA-B $(n=70)$ & SGA-C $(n=55)$ & $P$-value \\
\hline \multicolumn{6}{|l|}{ Sociodemographic } \\
\hline Age (years), mean (SD) & $63.9(8.5)$ & $61.9(8.7)$ & $64.2(8.2)$ & $65.0(8.6)$ & 0.188 \\
\hline Male, n (\%) & I5I (89.9) & $35(81.4)$ & $64(91.4)$ & $52(94.5)$ & 0.086 \\
\hline \multicolumn{6}{|l|}{ Smoking status, n (\%) } \\
\hline Active smoker & $12(7.1)$ & $0(0.0)$ & $4(5.7)$ & $8(14.5)$ & \multirow[t]{3}{*}{0.003} \\
\hline Ex-smoker & I3I (78.0) & $31(72.1)$ & $56(80.0)$ & $44(80.0)$ & \\
\hline Nonsmoker & $25(14.9)$ & $12(27.9)$ & $10(14.3)$ & $3(5.5)$ & \\
\hline Smoking years, mean (SD) & $30.8(16.3)$ & $23.3(18.1)$ & $31.0(16.0)$ & $36.5(13.0)$ & $<0.001$ \\
\hline \multicolumn{6}{|l|}{ Disease condition } \\
\hline \multicolumn{6}{|l|}{ COPD stage, $\mathrm{n}(\%)$} \\
\hline GOLD I (mild) & $14(8.3)$ & $5(35.7)$ & $6(42.9)$ & $3(21.4)$ & \multirow[t]{4}{*}{0.039} \\
\hline GOLD 2 (moderate) & $54(32.1)$ & $19(35.2)$ & $24(44.4)$ & II (20.4) & \\
\hline GOLD 3 (severe) & $68(40.5)$ & $12(17.6)$ & $24(35.3)$ & $32(47.1)$ & \\
\hline GOLD 4 (very severe) & $32(19.0)$ & $7(21.9)$ & $16(50.0)$ & $9(28.1)$ & \\
\hline Predicted FEV, \%, mean (SD) & $49.3(23.1)$ & $53.5(19.4)$ & $50.6(26.8)$ & $44.3(19.9)$ & 0.123 \\
\hline AECOPD, ${ }^{a}$ mean $(S D)$ & $1.5(2.2)$ & $\mathrm{I} .3(1.7)$ & $1.8(2.9)$ & $1.3(1.2)$ & 0.378 \\
\hline \multicolumn{6}{|l|}{ Anthropometry } \\
\hline BMI $\left(\mathrm{kg} / \mathrm{m}^{2}\right)$, mean $(\mathrm{SD})$ & $20.0(3.2)$ & $23.5(2.5)$ & $20.4(1.7)$ & $16.7(1.5)$ & $<0.001$ \\
\hline $\operatorname{MAC}(\mathrm{cm})$, mean $(\mathrm{SD})$ & $25.5(2.8)$ & $28.3(1.9)$ & $25.9(1.8)$ & $22.8(2.0)$ & $<0.001$ \\
\hline TSF (mm), mean (SD) & $10.1(4.6)$ & $14.9(94.1)$ & $10.2(2.6)$ & $6.2(2.8)$ & $<0.001$ \\
\hline MAMC (cm), mean (SD) & $22.3(2.2)$ & $23.6(2.2)$ & $22.7(1.8)$ & $20.9(1.7)$ & $<0.001$ \\
\hline Weight (kg), mean (SD) & $50.6(8.9)$ & $59.0(7.9)$ & $51.9(5.9)$ & $42.3(4.9)$ & $<0.001$ \\
\hline Prevalence of weight loss, n (\%) & $137(8 \mid .5)$ & $30(69.8)$ & $55(78.6)$ & $52(94.5)$ & 0.005 \\
\hline Amount of weight loss in last 6 months $(\mathrm{kg})$, mean $(\mathrm{SD})$ & $1.6(2.4)$ & $0.4(1.7)$ & $\mathrm{I} .5(2.3)$ & $2.8(2.4)$ & $<0.001$ \\
\hline Percentage of weight loss in last 6 months, mean (SD) & $3.6(5.1)$ & $0.7(3.0)$ & $3.0(4.6)$ & $6.6(5.5)$ & $<0.001$ \\
\hline \multicolumn{6}{|l|}{ Dietary intake } \\
\hline Number of daily meals, mean (SD) & $2.8(0.9)$ & $3.3(1.1)$ & $2.6(0.7)$ & $2.7(0.9)$ & $<0.001$ \\
\hline$<3$ meals per day, $\mathrm{n}(\%)$ & $45(26.8)$ & $4(9.3)$ & $24(34.3)$ & $17(30.9)$ & \multirow[t]{3}{*}{$<0.001$} \\
\hline 3 meals per day, n (\%) & $112(66.7)$ & $30(69.8)$ & $46(65.7)$ & $36(65.5)$ & \\
\hline$>3$ meals per day, $\mathrm{n}(\%)$ & II (6.5) & $9(20.9)$ & $0(0.0)$ & $2(3.6)$ & \\
\hline Total El, mean (SD) & $1,305(399)$ & I,37I (379) & $1,322(439)$ & $1,233(356)$ & 0.215 \\
\hline Total protein intake, mean (SD) & $51.6(16.3)$ & $54.8(17.4)$ & $52.3(16.5)$ & $48.1(14.8)$ & 0.121 \\
\hline $\mathrm{El}^{\mathrm{b}}(\mathrm{kcal} / \mathrm{kg} / \mathrm{d})$, mean (SD) & $26.4(8.6)$ & $23.5(6.7)$ & $25.8(9.2)$ & $29.3(8.3)$ & 0.003 \\
\hline $\mathrm{Pl}^{\mathrm{c}}(\mathrm{g} / \mathrm{kg} / \mathrm{d})$, mean $(\mathrm{SD})$ & $1.04(0.34)$ & $0.94(0.30)$ & $1.02(0.33)$ & $1.15(0.34)$ & 0.008 \\
\hline \%EER, ${ }^{d}$ mean (SD) & $74.8(23.5)$ & $78.4(22.2)$ & $73.7(26.3)$ & $73.3(20.7)$ & 0.508 \\
\hline$\% E P R,{ }^{e}$ mean $(S D)$ & $69.1(22.7)$ & $78.3(25.3)$ & $67.8(22.3)$ & $63.8(19.0)$ & 0.005 \\
\hline EER met, n (\%) & $24(14.3)$ & $8(18.6)$ & $10(14.3)$ & $6(10.9)$ & 0.558 \\
\hline EPR met, $\mathrm{n}(\%)$ & $25(14.9)$ & $9(20.9)$ & $7(10.0)$ & $9(16.4)$ & 0.282 \\
\hline \multicolumn{6}{|l|}{ QoL } \\
\hline SGRQ symptom score & $54.9(20.4)$ & $50.3(19.1)$ & $54.3(22.3)$ & $59.3(18.1)$ & 0.086 \\
\hline SGRQ activity score & $63.3(28.5)$ & $55.2(26.7)$ & $62.0(32.8)$ & $71.2(21.8)$ & 0.019 \\
\hline SGRQ impact score & $38.2(20.2)$ & $31.7(17.8)$ & $36.8(21.9)$ & $44.9(18.1)$ & 0.004 \\
\hline SGRQ total score & $48.6(21.1)$ & $41.9(19.2)$ & $47.4(23.5)$ & $55.4(17.3)$ & 0.006 \\
\hline
\end{tabular}

Notes: a Number of acute exacerbations in the last 12 months; B/C, $1.5 \mathrm{~g} / \mathrm{kg}$ body weight per day; ${ }^{\mathrm{b}} \mathrm{El}$ per $\mathrm{kg}$ actual body weight; $\mathrm{cPl}$, protein intake per $\mathrm{kg}$ actual body weight; ${ }^{d}$ EER (30 kcal//kg body weight per day for SGA-A; $35-40 \mathrm{kcal} / \mathrm{kg}$ body weight per day for SGA-B/C); ${ }^{\mathrm{e} E P R}$ (SGA-A: $1.2 \mathrm{~g} / \mathrm{kg}$ body weight per day; SGA-B/C: $1.5 \mathrm{~g} / \mathrm{kg}$ body weight per day). Boldface indicates statistical significance $(P<0.05)$.

Abbreviations: AECOPD, acute exacerbations of COPD; BMI, body mass index; EER, estimated energy requirement; El, energy intake; EPR, estimated protein requirement; GOLD, Global Initiative for Chronic Obstructive Lung Disease; MAC, mid-arm circumference; MAMC, mid-arm muscle circumference; QoL, quality of life; SGA, Subjective Global Assessment; SGRQ, St George Respiratory Questionnaire; TSF, triceps skinfold. 
Most participants (81.5\%) reported weight loss in the previous 6 months. More severely malnourished participants were more likely to have experienced and had larger amounts of weight loss ( $P<0.01,<0.001$, respectively).

As shown in Table 1, those participants who were malnourished (SGA-B+C) reported fewer daily meals than those with normal nutritional status (SGA-A; $P<0.001$ ). Prevalence of malnutrition (SGA-B/C) was found to be the highest among those having less than three meals per day $(91.1 \%)$, followed by those having three meals per day (73.2\%), and lowest among those having more than three meals per day (18.2\%), and this was significant $(P<0.001$; Table 1).

Due to traditional beliefs, with "cold" foods claimed to exacerbate coughing, nearly half of participants (42.3\%) avoided at least one kind of protein-rich food such as seafood (69.0\%), beef or buffalo meat (40.8\%), peanuts or sesame seeds (36.6\%), and poultry meat (chicken or duck, $25.4 \%$ ). Lactose intolerance was the reason given for milk avoidance (7.0\%; data not presented in table). This indicates a lower diversity of protein-rich foods from which the participants could choose.

On average, study participants consumed $26.4 \mathrm{kcal} / \mathrm{kg}$ body weight per day (SD: 8.6 ) and $1.04 \mathrm{~g}$ protein $/ \mathrm{kg}$ body weight per day (SD: 0.34). Those with severe malnutrition consumed more energy and protein compared to those with normal nutrition $(P<0.01)$, when energy intake (EI) or protein intake (PI) is expressed according to body weight's requirements. The \%EPR achieved by malnourished participants was significantly $(P=0.005)$ lower than that for well-nourished participants. The \%EER achieved by malnourished participants was lower than that in wellnourished participants but not significant $(P=0.508)$.
Most of participants did not meet their EER and EPR (85.7\% and $85.1 \%$, respectively).

Mean total and subscores for the SGRQ indicated that the sample had substantially reduced QoL, especially within the activity component. The mean total SGRQ score was 48.6 (SD 21.1). For subcategories, the highest score was for the activity component (63.3, SD: 28.5), followed by the symptom (54.9, SD: 20.4) and impact components (38.2, SD: 20.2). Those with severe malnutrition scored significantly higher (poorer QoL) on the activity, impact, and total scores than those with normal nutrition $(P<0.02)$.

\section{Malnutrition and related factors}

The overall logistic regression model was significant $(P<0.001$; Table 2). Only number of meals and BMI were significant predictors of malnourishment $(P<0.01)$. Increasing number of meals and increasing BMI were both associated with reduced odds of malnourishment (5.6 and 3.4 times, respectively). Number of years smoked ( $P=0.088$; increased odds of malnourishment) and EER\% met ( $P=0.056$; decreased odds of malnourishment) were both trending toward significance.

\section{QoL and related factors}

Total QoL score and subscores, except symptom componence, were significantly associated with nutritional status and disease severity (Table S1, Figure S1). Age, gender, and smoking years (Block 1) accounted for a nonsignificant $4 \%$ of the variance in the total QoL scores $(P=0.069$; Table 3). The addition of number of exacerbations and $\mathrm{FEV}_{1} \%$ in Block 2 accounted for a further significant $19 \%$ of variance in total $\mathrm{QoL}$ scores $(P<0.001)$. The addition of \%EER and number of daily meals and BMI (Block 3 )

Table 2 Logistic regression model for predicting malnutrition

\begin{tabular}{|c|c|c|c|c|c|c|}
\hline Variables & Block & $P$-value & Model & $P$-value & B & OR $(95 \% \mathrm{Cl})$ \\
\hline Model fit & 105.1 & $<0.001$ & 119.8 & $<0.001$ & & \\
\hline \multicolumn{7}{|l|}{ Variables } \\
\hline Age & & & & & 0.026 & I.03 (0.94-I.I2) \\
\hline Gender & & & & & -0.691 & $0.50(0.04-6.07)$ \\
\hline Smoke ${ }^{a}$ & & & & & 0.043 & $1.04(0.99-1.10)$ \\
\hline $\mathrm{AECOPD}^{\mathrm{b}}$ & & & & & -0.136 & $0.87(0.68-1.12)$ \\
\hline $\mathrm{FEV}_{1} \%$ & & & & & 0.010 & $1.01(0.98-1.04)$ \\
\hline$\% \mathrm{EER}^{\mathrm{c}}$ & & & & & -0.28 & $0.97(0.94-1.00)$ \\
\hline N_meal ${ }^{d}$ & & & & & -1.69 & $0.18(0.05-0.63)$ \\
\hline BMI & & & & & -1.25 & $0.29(0.18-0.47)$ \\
\hline
\end{tabular}

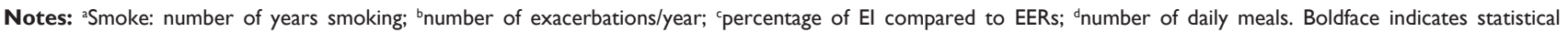
significance $(P<0.05)$.

Abbreviations: AECOPD, acute exacerbation of COPD; BMI, body mass index; EER, estimated energy requirement; El, energy intake. 
Table 3 Hierarchical regression model for prediction of QoL - total

\begin{tabular}{|c|c|c|c|c|c|c|c|}
\hline Variables & $R$ & $R^{2}$ & Adjusted $R^{2}$ & $R^{2}$ change & $P$-value & Unstandardized B & Standardized B \\
\hline Block I & 0.205 & 0.042 & 0.025 & 0.042 & 0.069 & & \\
\hline Age & & & & & & 0.288 & 0.116 \\
\hline Gender & & & & & & -8.76 & -0.126 \\
\hline Smoke ${ }^{a}$ & & & & & & 0.057 & 0.045 \\
\hline Block 2 & 0.477 & 0.228 & 0.204 & 0.185 & 0.001 & & \\
\hline Age & & & & & & 0.410 & 0.165 \\
\hline Gender & & & & & & -8.52 & -0.122 \\
\hline Smoke & & & & & & -0.003 & -0.002 \\
\hline $\mathrm{AECOPD}^{\mathrm{b}}$ & & & & & & 2.65 & 0.270 \\
\hline $\mathrm{FEV}, \%$ & & & & & & $-0.28 I$ & -0.307 \\
\hline Block 3 & 0.592 & 0.351 & 0.318 & 0.123 & 0.001 & & \\
\hline Age & & & & & & 0.420 & 0.169 \\
\hline Gender & & & & & & -1.62 & -0.023 \\
\hline Smoke & & & & & & 0.037 & 0.028 \\
\hline AECOPD & & & & & & 2.33 & 0.238 \\
\hline $\mathrm{FEV}_{1} \%$ & & & & & & -0.295 & -0.322 \\
\hline \%EER ${ }^{c}$ & & & & & & -0.260 & -0.290 \\
\hline N_meals ${ }^{d}$ & & & & & & -3.61 & -0.158 \\
\hline BMI & & & & & & -0.322 & -0.049 \\
\hline
\end{tabular}

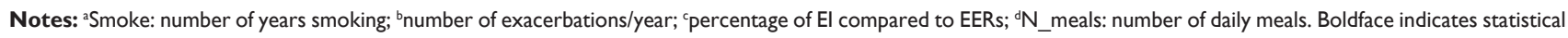
significance $(P<0.05)$.

Abbreviations: AECOPD, acute exacerbation of COPD; BMI, body mass index; EER, estimated energy requirement; El, energy intake; QoL, quality of life.

accounted for a further significant $12 \%$ of variance in total QoL $(P<0.001)$. Significant predictors in the final model (Block 3) were age, number of exacerbations, $\mathrm{FEV}_{1} \%$, $\%$ EER, and number of daily meals $(P<0.03)$. Using unstandardized beta coefficients, a one unit increase in number of exacerbations would produce a 2.33 unit increase in total QoL. A one unit increase in number of meals would produce a 3.61 unit decrease in total QoL. Similar results were found for QoL symptoms, activity, and impact (Tables S2-S4).

\section{Discussion}

The present study highlighted a high prevalence of malnutrition, inadequate energy, and protein intake and low QoL in this sample of COPD outpatients. Nearly three-quarters of this sample with COPD in Vietnam were malnourished. This is considerably higher than previous studies involving populations from high-income countries $(10 \%-45 \%),{ }^{36,37}$ but is in line with a recent review statement indicating that the prevalence of malnutrition in COPD is higher in lowincome countries. ${ }^{11}$ It is however also higher than a recent study conducted in Ho Chi Minh City, a southern province of Vietnam (45\%). ${ }^{12}$ This may be due to the NLH being a specialist hospital and receiving more severe COPD patients, this study and other previous studies found that malnutrition is higher in patients with more severe COPD..$^{37,38}$

While only a small number of participants were active smokers, smoking has previously been identified as a factor influencing malnutrition risk. ${ }^{39}$ Previous studies reveal that nicotine in tobacco affects body weight by increasing metabolic rate, decreasing metabolic efficiency through the release of hormones that influence appetite or reduce eating, and decreasing energy absorption, thereby facilitating weight loss. ${ }^{40,41}$ In addition, smokers in low-income countries tend to purchase less food due to tobacco expenditure and the food they do purchase seems to be of lower quality adversely affecting nutrition status. ${ }^{42}$ Thus, the longer and more severe the addiction to tobacco, the higher the risk of malnutrition. The association between smoking and nutritional status is again highlighted when we found evidence that the mean total of smoking years is highest among those who were diagnosed with severe malnutrition. The mean age of our participants was 64 years and they had been smoking for up to 36 years. This raises an urgent need for public health efforts to reduce smoking rates and the inclusion of smoking cessation advice during early stages of COPD diagnosis that should be repeated routinely in parallel with nutrition counseling sessions. ${ }^{43}$ 
In COPD, systematic inflammation may cause anorexia associated with the arterial partial pressure of oxygen and therefore create greater risk of undernutrition and pulmonary cachexia. ${ }^{36,44}$ This study used SGA as the diagnostic tool to identify malnourished patients and found that even in groups who had a healthy weight and who were overweight (according to WHO classifications for BMI), patients with COPD were still at risk of malnutrition $(78.3 \%$ and $18.5 \%$, respectively). This suggests that phenotype is not necessarily indicative of a COPD patient's nutritional status and overweight status could hide muscle depletion. In fact, fat-free mass index has been shown to be a better marker compared to BMI. ${ }^{44} \mathrm{BMI}$ alone therefore may not be adequate as a nutrition screening tool for COPD patients as it lacks sensitivity. It has been suggested that the only prompt, reliable method to assess nutritional status in COPD is via nutrition assessment instruments such as SGA. ${ }^{45}$

Weight loss is common in COPD due to an imbalance between EI requirement and expenditure. ${ }^{36}$ Most of the participants in this study (81.5\%) experienced weight loss and on average they lost $1.6 \mathrm{~kg}$ (SD: 2.4 ) in the previous 6 months. This is again higher than in previous studies where $10 \%-15 \%$ of mild COPD and $50 \%$ of severe COPD patients had lost weight. ${ }^{46}$ Noticeably, severely malnourished participants experienced greater weight loss than those who were mildly malnourished or well nourished. Due to the cross-sectional nature of this study, it is unclear if the weight loss continued. Several studies have pointed out that a weight gain of $2.0 \mathrm{~kg}$ or more will improve functional capacity and QoL among patients with COPD. ${ }^{20}$ Therefore, preventing weight loss should be one of the primary goals of nutrition intervention strategies in COPD patients.

In addition to the decreased dietary intake and increased energy expenditure, COPD is often associated with muscle depletion that is caused by increased rate of protein degradation and decreased rate of protein synthesis ${ }^{47}$ and this is worse with aging. ${ }^{31}$ In recent nutrition guidelines for elderly, high energy and protein diets are recommended..$^{28,30,31}$ This study found that most of participants (more than $80 \%$ ) did not meet their energy and protein requirements. In addition, severely malnourished COPD patients achieved lower energy and protein intakes and had fewer meals per day than well-nourished patients. A quarter of participants had only two meals per day and nearly half of participants avoided several protein-rich foods due to traditional beliefs. These factors detract from optimizing the eating habits of COPD patients and indicate the need to emphasize the importance of having more meals per day and encouraging daily food diversity. Although the advice that COPD patients should consume more small meals per day is mentioned commonly in nutrition guidelines, to date no studies have provided empirical evidence that additional meals support improvements in nutritional status. This study found that with an extra meal a day the odds of having malnutrition decreased 5.6 times (see Table 2). This important finding supports practical recommendations to consume more meals. This simple strategy could potentially benefit COPD patients in preventing weight loss, promoting weight gain, and improving nutritional status.

In agreement with other studies, our participants had their HRQL markedly impaired across all levels of malnutrition and COPD severity. ${ }^{25,48}$ Low body weight or other compromised anthropometric measurements and long smoking history were associated with greater impairment in HRQL score. This study also found nutritional status was correlated with lung function and HRQL. Previous studies reported the effectiveness of nutrition interventions in improving functional capacity and HRQL in COPD patients. ${ }^{13,49-51}$ Among several factors related to HRQL and malnutrition status described in this study, we found that the most significant factor which is feasibly modifiable is the number of meals that participants consume per day. An extra meal per day would help reduce SGRQ total and subscores by a range of 2.5-5.2 points, indicating a better HRQL. Research has indicated that a four point improvement in SGRQ score can contribute to a change in clinical outcomes. ${ }^{48,52}$ This again emphasizes that a strategy to encourage COPD patients to add more meals a day may help to improve not only nutritional status but also HRQL. Further studies are needed to confirm the effectiveness of this simple practice.

Most recent studies focus on the addition of dairy-based supplements rather than dietary advice alone in intervening nutrition for patients with COPD. This may not be relevant for Vietnamese elderly due to high rate of lactose intolerance. ${ }^{53}$ In addition, milk and dairy products are expensive in Vietnam and other regional countries. Tailored dietary advice therefore, rather than supplements, may be a potential strategy with greater impact for improving nutritional status, functional capacity, and QoL in low-resourced nondairybased cultures. ${ }^{54}$ Based on findings from this present study, nutrition counseling for COPD patients should include the following key messages: 1) increase the number of meals consumed per day by ensuring three main meals and adding snacks between meals; 2) broaden the diversity of foods incorporated, especially protein-rich foods such as all kinds of meats, poultry, seafood, eggs, milk, and nuts; and 3) choose energy- and protein-rich foods that are available, accessible, and affordable relevant to an individual patient's context. 
Nevertheless, there are some important limitations that call for caution in the interpretation of our findings. While multipass recalls are best practice and should include a weekend day, only one day could be collected due to time and resourcing constraints. In addition, this study failed to detect other underlying disease that may have impact on patient weight due to limited resources. However, the findings of this study provided useful information for developing a nutrition intervention strategy for Vietnamese COPD outpatients that will be useful for future work in this population.

\section{Conclusion}

Given the burden of COPD and the combination of poor dietary intake and impaired HRQL with the high prevalence of malnutrition, there is an urgent need for nutrition intervention in COPD outpatients in Vietnam. The findings from this study provide a valuable insight into the potential barriers and enablers for the management of malnutrition in this patient group. This study highlighted some key nutrition messages that encourage COPD patients to have more meals and consider daily consumption of energy- and protein-rich foods as a priority in order to improve their nutritional status, functional capacity, and QoL.

\section{Data sharing statement}

Nonidentified data presented in this article, may be made available on request from the lead author.

\section{Acknowledgments}

The authors are grateful to $\mathrm{Dr} \mathrm{Vu}$ Van Thanh, Ms Vu Thi Thanh Ngan, and all staff of the COPD Management Unit of National Lung Hospital Vietnam for their time and effort in helping collect data for this study, Dr Tran Chau Quyen from the National Institute of Nutrition for her advice on dietary data collection, Dr Mary Hannan-Jones from the School of Exercise and Nutrition Sciences, Queensland University of Technology for her advice on the dietary analysis, and all Vietnamese COPD patients involved in this study.

\section{Author contributions}

HTN determined the key concepts for the paper, completed ethics, conducted the research in Vietnam as part of her $\mathrm{PhD}$ program under the supervision and guidance of DLG, NVN, TDP, TGP and PFC. Data collection and entry was conducted by HTN. All authors contributed to data analysis, drafting or revising the article, gave final approval of the version to be published, and agree to be accountable for all aspects of the work.

\section{Disclosure}

This study is a part of $\mathrm{PhD}$ research undertaken by Dr Nguyen Thanh Ha, an Australia Award Scholarship Awardee at the Queensland University of Technology, Australia. The lead author affirms that this paper is an honest, accurate, and transparent account of the study being reported. The reporting of this work is compliant with STROBE guidelines. The lead author affirms that no important aspects of the study have been omitted and that any discrepancies from the study as planned have been explained. The authors report no conflicts of interest in this work.

\section{References}

1. Vos T, Flaxman AD, Naghavi M, et al. Years lived with disability (YLDs) for 1160 sequelae of 289 diseases and injuries 1990-2010: a systematic analysis for the Global Burden of Disease Study 2010. Lancet. 2012;380(9859):2163-2196.

2. Soriano JB, Abajobir AA, Abate KH. GBD 2015 Chronic Respiratory Disease Collaborators. Global, regional, and national deaths, prevalence, disability-adjusted life years, and years lived with disability for chronic obstructive pulmonary disease and asthma, 1990-2015: a systematic analysis for the Global Burden of Disease Study 2015. Lancet Respir Med. 2017;5(9):691-706.

3. Vogelmeier CF, Criner GJ, Martinez FJ, et al. Global Strategy for the diagnosis, management and prevention of chronic obstructive lung disease 2017 report: GOLD executive summary. Respirology. 2017;22(3): 575-601.

4. Lim S, Lam DC, Muttalif AR, et al. Impact of chronic obstructive pulmonary disease (COPD) in the Asia-Pacific region: the EPIC Asia population-based survey. Asia Pac Fam Med. 2015;14(1):4.

5. Teramoto S, Yamamoto H, Yamaguchi Y, Matsuse T, Ouchi Y. Global burden of COPD in Japan and Asia. Lancet. 2003;362(9397): 1764-1765.

6. Fang L, Gao P, Bao H, et al. Chronic obstructive pulmonary disease in China: a nationwide prevalence study. Lancet Respir Med. 2018;6(6): 421-430.

7. Nguyen Viet N, Yunus F, Nguyen Thi Phuong A, et al. The prevalence and patient characteristics of chronic obstructive pulmonary disease in non-smokers in Vietnam and Indonesia: an observational survey. Respirology. 2015;20(4):602-611.

8. Salvi SS, Barnes PJ. Chronic obstructive pulmonary disease in nonsmokers. Lancet. 2009;374(9691):733-743.

9. Schols AM, Ferreira IM, Franssen FM, et al. Nutritional assessment and therapy in COPD: a European Respiratory Society statement. Eur Respir J. 2014;44(6):1504-1520.

10. Collins PF, Elia M, Stratton RJ. Nutritional support and functional capacity in chronic obstructive pulmonary disease: a systematic review and meta-analysis. Respirology. 2013;18(4):616-629.

11. Sehgal IS, Dhooria S, Agarwal R. Chronic obstructive pulmonary disease and malnutrition in developing countries. Curr Opin Pulm Med. 2017;23(2):139-148.

12. Hogan D, Lan LT, Diep DT, Gallegos D, Collins PF. Nutritional status of Vietnamese outpatients with chronic obstructive pulmonary disease. J Hum Nutr Diet. 2017;30(1):83-89.

13. Chambaneau A, Filaire M, Jubert L, Bremond M, Filaire E. Nutritional intake, physical activity and quality of life in COPD patients. Int J Sports Med. 2016;37(9):730-737.

14. Hoong JM, Ferguson M, Hukins C, Collins PF. Economic and operational burden associated with malnutrition in chronic obstructive pulmonary disease. Clin Nutr. 2017;36(4):1105-1109. 
15. Collins PF, Stratton RJ, Kurukulaaratchy RJ, Elia M. Influence of deprivation on health care use, health care costs, and mortality in COPD. Int J Chron Obstruct Pulmon Dis. 2018;13:1289-1296.

16. Laudisio A, Costanzo L, di Gioia C, et al. Dietary intake of elderly outpatients with chronic obstructive pulmonary disease. Arch Gerontol Geriatr. 2016;64:75-81.

17. Ter Beek L, van der Vaart H, Wempe JB, et al. Dietary resilience in patients with severe COPD at the start of a pulmonary rehabilitation program. Int J Chron Obstruct Pulmon Dis. 2018;13:1317-1324.

18. Rawal G, Yadav S. Nutrition in chronic obstructive pulmonary disease: a review. J Transl Int Med. 2015;3(4):151-154.

19. Collins PF, Stratton RJ, Elia M. Nutritional support in chronic obstructive pulmonary disease: a systematic review and meta-analysis. Am J Clin Nutr. 2012;95(6):1385-1395.

20. Ferreira IM, Brooks D, White J, Goldstein R; Cochrane Airways Group. Nutritional supplementation for stable chronic obstructive pulmonary disease. Cochrane Database Syst Rev. 2012;12:CD000998.

21. Sugawara K, Takahashi H, Kasai C, et al. Effects of nutritional supplementation combined with low-intensity exercise in malnourished patients with COPD. Respir Med. 2010;104(12):1883-1889.

22. Detsky AS, McLaughlin JR, Baker JP, et al. What is subjective global assessment of nutritional status? JPEN J Parenter Enteral Nutr. 1987; 11(1):8-13.

23. WHO Expert Consultation. Appropriate body-mass index for Asian populations and its implications for policy and intervention strategies. Lancet. 2004;363(9403):157.

24. Jones P, Forde Y. St George's Respiratory Questionnaire for COPD Patients (SGRQ-C) Manual 2008. UK: Division of Cardiac and Vascular Science, St George's, University of London, London. Health Related Quality; 2012.

25. Wacker ME, Jörres RA, Karch A, et al. Assessing health-related quality of life in COPD: comparing generic and disease-specific instruments with focus on comorbidities. BMC Pulm Med. 2016;16(1):70.

26. Agarwal A, Gupta D, Kumar T. Validation of Hindi translation of St. George's Respiratory Questionnaire in Indian patients with chronic obstructive pulmonary disease. Indian J Chest Dis Allied Sci. 2007;49: 87-92.

27. National Institute of Nutrition (NIN). Vietnamese Food Composition Table. Hanoi, Vietnam: Medical Publishing House; 2007.

28. Raynaud-Simon A, Revel-Delhom C, Hébuterne X. Clinical practice guidelines from the French Health High Authority: nutritional support strategy in protein-energy malnutrition in the elderly. Clin Nutr. 2011;30(3):312-319.

29. Anker SD, John M, Pedersen PU, et al. ESPEN guidelines on enteral nutrition: cardiology and pulmonology. Clin Nutr. 2006;25(2):311-318.

30. Bauer J, Biolo G, Cederholm T, et al. Evidence-based recommendations for optimal dietary protein intake in older people: a position paper from the PROT-AGE Study Group. J Am Med Dir Assoc. 2013;14(8):542-559.

31. Morley JE, Thomas DR. Geriatric Nutrition. Florida: Chapman and Hall/CRC Press; 2007.

32. Deutz NE, Bauer JM, Barazzoni R, et al. Protein intake and exercise for optimal muscle function with aging: recommendations from the ESPEN Expert Group. Clin Nutr. 2014;33(6):929-936.

33. Weekes CE, Emery PW, Elia M. A randomised trial of dietary counselling and food fortification in stable chronic obstructive pulmonary disease. Thorax. 2009;64:326-331.

34. Templeton GF. A two-step approach for transforming continuous variables to normal: implications and recommendations for IS research. CAIS. 2011;28(1):41-58.
35. von Elm E, Altman DG, Egger M, Pocock SJ, Gøtzsche PC, Vandenbroucke JP. The Strengthening the Reporting of Observational Studies in Epidemiology (STROBE) statement: guidelines for reporting observational studies. Lancet. 2007;370(9596):1453-1457.

36. Stratton RJ, Green CJ, Elia M. Disease-Related Malnutrition: An Evidence-Based Approach to Treatment. Oxfordshire: CABI; 2003.

37. Humphreys K, Cross G, Frith P, Cafarella P. Nutritional status and dietary intake of outpatients with chronic obstructive pulmonary disease. Nutr Diet. 2008;65(2):168-174.

38. Cochrane WJ, Afolabi OA. Investigation into the nutritional status, dietary intake and smoking habits of patients with chronic obstructive pulmonary disease. J Hum Nutr Diet. 2004;17(1):3-11.

39. Collins PF, Stratton RJ, Elia M. The influence of smoking status on malnutrition risk and 1-year mortality in outpatients with chronic obstructive pulmonary disease. J Hum Nutr Diet. 2011;24(4):382-383.

40. Audrain-Mcgovern J, Benowitz NL. Cigarette smoking, nicotine, and body weight. Clin Pharmacol Ther. 2011;90(1):164-168.

41. Valassi E, Scacchi M, Cavagnini F. Neuroendocrine control of food intake. Nutr Metab Cardiovasc Dis. 2008;18(2):158-168.

42. Block S, Webb P, Steven Block PW. Up in smoke: tobacco use, expenditure on food, and child malnutrition in developing countries. Econ Devel Cult Change. 2009;58(1):1-23.

43. Collins PF, Stratton RJ, Elia M. The influence of smoking status on malnutrition risk and 1-year mortality in outpatients with chronic obstructive pulmonary disease. J Hum Nutr Diet. 2011;24(4):382-383.

44. Schols AM. The 2014 ESPEN Arvid Wretlind Lecture: metabolism \& nutrition: shifting paradigms in COPD management. Clin Nutr. 2015; 34(6):1074-1079.

45. Collins PF. Nutrition support in pulmonary and cardiac disease. In: Hickson M, Smith S (eds) Advanced Nutrition and Dietetics in Nutritional Support. 2018:270-277.

46. Schols AM, Soeters PB, Dingemans AM, Mostert R, Frantzen PJ, Wouters EF. Prevalence and characteristics of nutritional depletion in patients with stable COPD eligible for pulmonary rehabilitation. Am Rev Respir Dis. 1993;147(5):1151-1156.

47. Wüst RC, Degens H. Factors contributing to muscle wasting and dysfunction in COPD patients. Int J Chron Obstruct Pulmon Dis. 2007; 2(3):289.

48. Jones PW, Brusselle G, Dal Negro RW, et al. Health-related quality of life in patients by COPD severity within primary care in Europe. Respir Med. 2011;105(1):57-66.

49. Planas M, Álvarez J, García-Peris PA, et al. Nutritional support and quality of life in stable chronic obstructive pulmonary disease (COPD) patients. Clin Nutr. 2005;24(3):433-441.

50. Suzana S Jr, Hanis MY, Tang SY, Ayiesah R, Roslina AM. Changes in nutritional, functional status and quality of life of COPD out-patients after a pulmonary rehabilitation programme in HUKM: a pilot study. Malays J Nutr. 2008;14(2):151-162.

51. Kwon HY, Kim E. Factors contributing to quality of life in COPD patients in South Korea. Int J Chron Obstruct Pulmon Dis. 2016;11:103.

52. Feldman GJ. Improving the quality of life in patients with chronic obstructive pulmonary disease: focus on indacaterol. Int J Chron Obstruct Pulmon Dis. 2013;8:89.

53. di Stefano M, Veneto G, Malservisi S, Strocchi A, Corazza GR. Lactose malabsorption and intolerance in the elderly. Scand J Gastroenterol. 2001;36(12):1274-1278.

54. Eyles HC, Mhurchu CN. Does tailoring make a difference? A systematic review of the long-term effectiveness of tailored nutrition education for adults. Nutr Rev. 2009;67(8):464-480. 


\section{Supplementary materials}

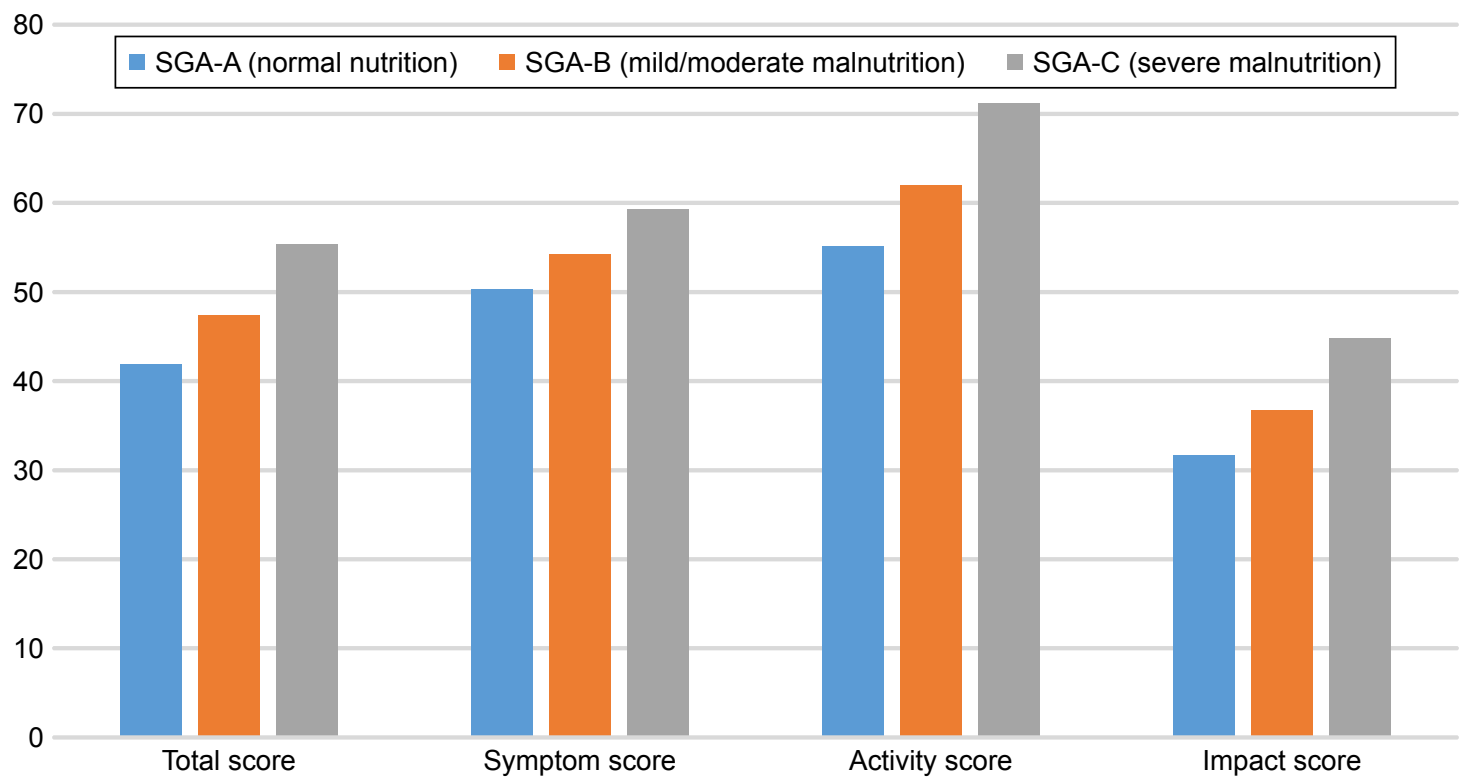

Figure SI The relationship between nutritional status and QoL's score (higher score indicates poorer QoL). Abbreviations: QoL, quality of life; SGA, Subjective Global Assessment.

Table SI Quality of life and related factors

\begin{tabular}{|c|c|c|c|c|c|c|c|c|}
\hline Variables & Symptom & $P$-value & Activity & $P$-value & Impact & $P$-value & Total & $P$-value \\
\hline \multicolumn{9}{|l|}{ Disease severity } \\
\hline GOLD I & $51.0(27.0)$ & \multirow[t]{4}{*}{0.179} & $47.6(34.4)$ & \multirow[t]{4}{*}{$<0.001$} & $34.1(21.9)$ & \multirow[t]{4}{*}{0.017} & 40.9 (25.2) & \multirow[t]{4}{*}{0.001} \\
\hline GOLD 2 & $52.1(23.0)$ & & $54.2(30.1)$ & & $33.9(21.7)$ & & 43.1 (23.3) & \\
\hline GOLD 3 & $54.9(17.7)$ & & $65.2(25.3)$ & & $37.9(19.4)$ & & 49.1 (18.7) & \\
\hline GOLD 4 & $61.5(16.8)$ & & $81.3(19.1)$ & & $47.6(16.0)$ & & 60.4 (14.9) & \\
\hline \multicolumn{9}{|l|}{ BMI categories } \\
\hline Underweight & $57.6(18.7)$ & \multirow[t]{4}{*}{0.124} & 7I.6 (22.9) & \multirow[t]{4}{*}{0.066} & $44.7(18.6)$ & \multirow[t]{4}{*}{0.031} & $55.2(18.0)$ & \multirow[t]{4}{*}{0.038} \\
\hline Normal & $55.2(21.7)$ & & $59.5(30.7)$ & & $35.3(20.8)$ & & $46.0(22.2)$ & \\
\hline Overweight & $47.4(18.4)$ & & $57.8(30.4)$ & & $33.6(19.9)$ & & $37.9(21.8)$ & \\
\hline Obesity & $67.6(16.8)$ & & $64.1(19.6)$ & & 37.8 (9.1) & & $50.8(9.8)$ & \\
\hline \multicolumn{9}{|l|}{ Nutritional status } \\
\hline SGA-A & $50.3(19.1)$ & \multirow[t]{3}{*}{0.086} & $55.2(26.7)$ & \multirow[t]{3}{*}{0.019} & $31.7(17.8)$ & \multirow[t]{3}{*}{0.004} & $41.9(19.2)$ & \multirow[t]{3}{*}{0.006} \\
\hline SGA-B & $54.3(22.3)$ & & $62.0(32.8)$ & & $36.8(21.9)$ & & 47.4 (23.5) & \\
\hline SGA-C & $59.3(18.1)$ & & $71.2(21.8)$ & & $44.9(18.1)$ & & $55.4(17.3)$ & \\
\hline Total score & $54.9(20.4)$ & NA & $63.3(28.5)$ & NA & $38.2(20.2)$ & NA & $48.6(21.1)$ & NA \\
\hline
\end{tabular}

Abbreviations: BMI, body mass index; GOLD, Global Initiative for Chronic Obstructive Lung Disease; SGA, subjective global assessment; SGA-A, normal nutritional status; SGA-B, mild/moderate malnutrition; SGA-C, severe malnutrition. 
Table S2 Hierarchical multiple regression for prediction of quality of life - symptoms

\begin{tabular}{|c|c|c|c|c|c|c|c|}
\hline Variables & $R$ & $R^{2}$ & Adjusted $R^{2}$ & $R^{2}$ change & $P$-value & Unstandardized B & Standardized $B$ \\
\hline Block I & 0.199 & 0.040 & 0.022 & 0.040 & 0.084 & & \\
\hline Age & & & & & & 0.402 & 0.167 \\
\hline Gender & & & & & & -5.74 & -0.085 \\
\hline Smoke ${ }^{a}$ & & & & & & 0.021 & 0.017 \\
\hline Block 2 & 0.448 & 0.201 & 0.176 & 0.161 & 0.001 & & \\
\hline Age & & & & & & 0.489 & 0.204 \\
\hline Gender & & & & & & -5.16 & -0.077 \\
\hline Smoke & & & & & & -0.030 & -0.024 \\
\hline Exacerbation $^{\mathrm{b}}$ & & & & & & 3.09 & 0.327 \\
\hline $\mathrm{FEV}_{1} \%$ & & & & & & -0.177 & -0.201 \\
\hline Block 3 & 0.530 & $0.28 I$ & 0.245 & 0.080 & 0.001 & & \\
\hline Age & & & & & & 0.531 & 0.221 \\
\hline Gender & & & & & & 0.991 & -0.015 \\
\hline Smoke & & & & & & 0.017 & 0.013 \\
\hline Exacerbation & & & & & & 2.81 & 0.297 \\
\hline $\mathrm{FEV}, \%$ & & & & & & -0.205 & -0.233 \\
\hline \%EER ${ }^{c}$ & & & & & & -0.173 & -0.199 \\
\hline N_meals ${ }^{d}$ & & & & & & -3.98 & -0.180 \\
\hline BMI & & & & & & 0.179 & 0.028 \\
\hline
\end{tabular}

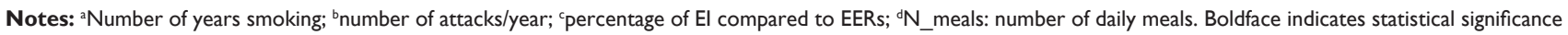
$(P<0.05)$.

Abbreviations: BMI, body mass index; EER, estimated energy requirement; El, energy intake.

Table S3 Hierarchical multiple regression for prediction of quality of life - activity

\begin{tabular}{|c|c|c|c|c|c|c|c|}
\hline Variables & $R$ & $R^{2}$ & Adjusted $R^{2}$ & $R^{2}$ change & $P$-value & Unstandardized B & Standardized B \\
\hline Block I & 0.198 & 0.039 & 0.022 & 0.039 & 0.087 & & \\
\hline Age & & & & & & 0.452 & 0.135 \\
\hline Gender & & & & & & -12.67 & -0.134 \\
\hline Smoke ${ }^{a}$ & & & & & & 0.016 & 0.009 \\
\hline Block 2 & 0.486 & 0.236 & 0.213 & 0.197 & 0.001 & & \\
\hline Age & & & & & & 0.639 & 0.190 \\
\hline Gender & & & & & & -12.76 & -0.135 \\
\hline Smoke & & & & & & -0.070 & -0.040 \\
\hline Exacerbation ${ }^{\mathrm{b}}$ & & & & & & 2.80 & 0.211 \\
\hline $\mathrm{FEV}_{1} \%$ & & & & & & -0.456 & -0.369 \\
\hline Block 3 & 0.605 & 0.365 & 0.334 & 0.129 & 0.001 & & \\
\hline Age & & & & & & 0.660 & 0.196 \\
\hline Gender & & & & & & -2.59 & -0.027 \\
\hline Smoke & & & & & & 0.001 & 0.000 \\
\hline Exacerbation & & & & & & 2.34 & 0.177 \\
\hline $\mathrm{FEV}, \%$ & & & & & & -0.489 & -0.395 \\
\hline \%EER ${ }^{c}$ & & & & & & -0.361 & -0.298 \\
\hline N_meals ${ }^{d}$ & & & & & & -5.20 & -0.168 \\
\hline BMI & & & & & & 0.123 & -0.014 \\
\hline
\end{tabular}

Notes: ${ }^{2}$ Number of years smoking; ${ }^{b}$ number of attacks/year; ' ${ }^{2}$ ercentage of El compared to EERs; ${ }^{d} \mathrm{~N} \_$meals: number of daily meals. Boldface indicates statistical significance $(P<0.05)$.

Abbreviations: BMI, body mass index; EER, estimated energy requirement; El, energy intake. 
Table S4 Hierarchical multiple regression for prediction of quality of life - impact

\begin{tabular}{|c|c|c|c|c|c|c|c|}
\hline Variables & $R$ & $R^{2}$ & Adjusted $R^{2}$ & $R^{2}$ change & $P$-value & Unstandardized B & Standardized B \\
\hline Block I & 0.187 & 0.035 & 0.017 & 0.035 & 0.118 & & \\
\hline Age & & & & & & 0.152 & 0.064 \\
\hline Gender & & & & & & -7.21 & -0.108 \\
\hline Smoke ${ }^{a}$ & & & & & & 0.093 & 0.075 \\
\hline Block 2 & 0.408 & 0.167 & 0.141 & 0.132 & 0.001 & & \\
\hline Age & & & & & & 0.243 & 0.102 \\
\hline Gender & & & & & & -6.90 & -0.103 \\
\hline Smoke & & & & & & 0.045 & 0.036 \\
\hline Exacerbation $^{\mathrm{b}}$ & & & & & & 2.39 & 0.255 \\
\hline $\mathrm{FEV}_{1} \%$ & & & & & & -0.204 & -0.232 \\
\hline Block 3 & 0.512 & 0.262 & 0.225 & 0.095 & 0.001 & & \\
\hline Age & & & & & & 0.238 & 0.100 \\
\hline Gender & & & & & & -1.81 & -0.027 \\
\hline Smoke & & & & & & 0.064 & 0.052 \\
\hline Exacerbation & & & & & & 2.15 & 0.229 \\
\hline $\mathrm{FEV}_{1} \%$ & & & & & & -0.202 & -0.230 \\
\hline$\% \mathrm{EER}^{\mathrm{c}}$ & & & & & & -0.223 & -0.259 \\
\hline N_meals ${ }^{d}$ & & & & & & -2.50 & -0.114 \\
\hline BMI & & & & & & 0.590 & -0.093 \\
\hline
\end{tabular}

Notes: ${ }^{a}$ Number of years smoking; ${ }^{b}$ number of attacks/year; ${ }^{c}$ percentage of El compared to EERs; ${ }^{d} \mathrm{~N} \_$meals: number of daily meals. Boldface indicates statistical significance $(P<0.05)$.

Abbreviations: BMI, body mass index; EER, estimated energy requirement; El, energy intake.

\section{Publish your work in this journal}

The International Journal of COPD is an international, peer-reviewed journal of therapeutics and pharmacology focusing on concise rapid reporting of clinical studies and reviews in COPD. Special focus is given to the pathophysiological processes underlying the disease, intervention programs, patient focused education, and self management protocols.

\section{Dovepress}

This journal is indexed on PubMed Central, MedLine and CAS. The manuscript management system is completely online and includes a very quick and fair peer-review system, which is all easy to use. Visit http://www.dovepress.com/testimonials.php to read real quotes from published authors. 